\title{
COMPORTAMENTO LINGUÍSTICO, EMPIRIA E FILOSOFIA EM WITTGENSTEIN
}

\author{
Rafael Lopes Azize*
}

\begin{abstract}
Nos anos 1940, Wittgenstein aprofunda a expansão do campo criterial dos conceitos e da sua análise possível e desejável, na direção de uma maior inclusão, no formal, do vivido. O presente artigo examina algumas questões relativas à acusação de que, ao ampliar o âmbito de análise conceitual à prática (ou, como dizia o filósofo, ao "comportamento ritual”), Wittgenstein teria extraviado a sua sensibilidade filosófica em investigações estritamente empíricas, ou seja, filosoficamente irrelevantes.

Palavras-chave: Linguagem ordinária. Comportamento linguístico. Pragmática. Autonomia do Sentido. Austin. Wittgenstein.
\end{abstract}

Quando pedíamos por uma distinção entre o que é importante e o que não é importante (com isso, é claro, nos referíamos a uma distinção entre dados linguísticos que são e, novamente, que não são filosoficamente importantes), não raro éramos confrontados com a afirmação (também avançada ao final do artigo de Austin "Pretending") de que ele, Austin, não era muito bom em distinguir entre o que era e o que não era importante. (Paul Grice, 1987, p. 182)

Se examinarmos o percurso filosófico de Wittgenstein ao revés, poderemos identificar uma progressiva expansão do âmbito em que se colherão critérios de que depende o sentido em geral, por forma a incluir aí elementos pragmáticos. Tal expansão é uma das maneiras possíveis de indicar o porquê de haver o filósofo desejado que a sua filosofia tardia fosse lida sempre contra o pano de fundo do seu livro de juventude, o Tractatus no qual, justamente, se tratava de expurgar o sentido de quaisquer elementos extrínsecos à forma da proposição, representável, pensava o autor daquela obra, na sua máxima e definitiva generali-

* Doutor em Filosofia. Professor do Programa de Pós-Graduação em Filosofia da Universidade Federal da Bahia - UFBA. Estrada de São Lázaro, 197. Federação. Cep: 40210-730. Salvador - Bahia - Brasil. rafaelazize@gmail.com dade. A contraposição dos dois movimentos do pensamento (grosso modo, o Tractatus e as Investigações filosóficas) revelaria, assim, o espírito do "novo método", aquele de uma profilaxia contra generalizações máximas e definitivas, tão caras à tradição filosófica. A sugestão de leitura explicitada no próprio Prefácio das Investigações não é, contudo, livre de riscos. Gostaríamos de explorar um aspecto desses riscos, porventura útil para iluminar as relações entre ação significativa, empiria e filosofia no Wittgenstein tardio.

Nos anos 1940, conforme se aproxima o filósofo da derradeira etapa da expansão acima referida, em direção à extensão completa do conceito de experiência e à estruturação madura dos conceitos de 'uso' e de 'forma de vida', mais se abre a sua filosofia às críticas que seguiram $o$ tom daquela de Russell na sua autobiografia intelectual. ${ }^{1}$ Segundo tais críticas, o nosso filósofo

1 "O Wittgenstein tardio [...] parece ter-se cansado do pensamento sério, parece ter inventado uma doutrina que tornaria uma tal atividade desnecessária. Não me passa pela cabeça acreditar que é verdadeira uma doutrina que tenha consequências preguiçosas como essas. Reconheço, contudo, que tenho um preconceito incontrolavelmente forte contra ela, pois, se ela é verdadeira, a filosofia serve, no 
ter-se-ia extraviado em investigações cuja natureza seria já dificilmente caracterizável como filosófica, ou pelo menos como filosofia séria. A atenção especial conferida à linguagem como fenômeno no tempo e no espaço - ou, se se quiser, no limite, ao comportamento linguístico, a ação passível de descrição no contexto de uma teia de associações com outras ações significativas - se teria dado, nessa perspectiva, ao preço da sensibilidade para a filosofia. É interessante verificar que, em muitos círculos de interlocução filosófica cujo estilo é informado por Frege e seu comentário, a menção ao Wittgenstein tardio - que dirá a apresentação de novos esforços exegéticos da sua obra - tem começado a precisar justificar-se, a não ser encarada com a naturalidade do comentário e uso dos clássicos da disciplina. ${ }^{2}$ Isso é tanto mais curioso quanto Frege é uma das fontes principais, alguns diriam talvez a principal, dos temas, de vários traços de estilo e, em alguns aspectos, do método do nosso autor. ${ }^{3}$

Uma boa maneira de apreciar as razões por que ecoa a virulenta rejeição de Russell ao seu antigo aluno austríaco consiste, talvez, em levantar perguntas como estas: é, de fato, a filosofia tardia de Wittgenstein assimilável à chamada filosofia da linguagem ordinária? Mais ainda: aponta o método wittgensteiniano - uma investigação do que ele chama de variações de aspectos do uso de conceitos em situações restritas, imaginárias ou não, com vistas à representação panorâmica de jogos de linguagem nas suas redes de relações ou ligações intermediárias ${ }^{4}$ - para um trabalho filosófico que pouco se distinguiria de certos ramos da linguística,

melhor dos casos, como um pequeno auxílio a lexicógrafos, e no pior, é um divertimento de chá das cinco” (Russell, 1959, p. 216-217, trad. nossa).

${ }^{2}$ Veja-se, como exemplo, Miguens (2007).

${ }^{3}$ Em mais de um lugar, o próprio filósofo o afirma, como aqui: "O estilo das minhas sentenças é muito fortemente influenciado por Frege. E se eu o quisesse, poderia estabelecer essa influência ali onde à primeira vista ninguém a enxergaria.” (Z §712); “(Der Stil meiner Sätze ist außerordentlich stark von Frege beeinflusst. Und wenn ich wollte, so könnte ich wohl diesen Einfluss feststellen, wo ihn auf den ersten Blick keiner sähe)”.

${ }^{4}$ Permitimo-nos remeter a artigo nosso sobre a importante noção de Zwischengliedern: "Ligações intermediária e representação perspícua em Wittgenstein” (Azize, 2010 p. 119-132). ou da análise do discurso, dedicados à ação linguística? Há aqui semelhanças de família, mas com um alcance muito limitado. Interessa-nos ressaltar alguns aspectos mais gerais desse alcance limitado-os quais, incidentalmente, integram o tema mais amplo das relações entre conhecimento e ação. Estabelecer os seus limites é um requisito importante, ainda, para o delineamento daquilo que conta como análise conceitual no contexto criterial amplo do Wittgenstein tardio - a incluir, justamente, a ação significativa, massivamente constituída pelo que ele chamará de "comportamento ritual" (GB). Tal delineamento, por sua vez, parece-nos condição para que o leitor de Wittgenstein possa acatar as sugestões que o seu "novo método" nos deixou, em direção a uma maneira antidogmática (resguardada contra generalizações máximas e definitivas) de fazer filosofia.

Um importante ponto de partida filosófico comum a Wittgenstein e, por exemplo, a John Austin - talvez o filósofo que primeiro nos vem à mente quando pensamos no que Grice (1987) chama de abordagem da filosofia a partir da linguagem ordinária ou cotidiana - é a crítica ao essencialismo de tipo aristotélico. Examinemos alguns traços dessa crítica comum. A aproximação genealógica nos servirá, em seguida, para ressaltar diferenças importantes, ensejando uma resposta mais nuançada às perguntas do parágrafo anterior, e o retorno ao nosso tema principal.

Segundo uma concepção essencialista do conceito, um termo geral remete a um atributo ou conjunto de atributos essenciais, como que presentes em todas as instâncias que o termo geral organiza. Chega-se à essência de um conceito separando-se desse conceito o que lhe é acidental, ou seja, isolando-se apenas aquelas propriedades que são necessárias à inclusão ou exclusão, no conjunto organizado pelo termo geral, dos seus membros, conforme aquelas propriedades pertençam ou não, por assim dizer, a tais membros. Por exemplo, nessa perspectiva a afirmação de que Pedro seja homem parece dizer de Pedro algo mais essencial do que a afirmação de que ele tenha estatura mediana - o que, à primeira vista, é bastante razoável. Mas à medida que subjaz 
a essa concepção um tipo especial de determinismo, há aí certa ambição epistemológica que se impõe àquela primeira interpretação razoável. A esperança é a de que tal análise nos conduza à substância do elemento na posição de sujeito, uma certa noção daquilo que ele é em si mesmo e não poderia não ser. Oestabelecimento de predicações essenciais (nãoacidentais) deve, então, perfazer uma análise do estofo ontológico do mundo, levando a que se interprete a cópula do ser como uma expressão exclusivamente de identidade.

A imagem paradigmática das asserções com que trabalha a silogística tradicional ('S é P', alguma coisa e o que se diz dela) sugere que os membros de um conjunto como que manifestam esse conjunto de maneira homogênea. Por outras palavras, certos atributos seriam inerentes às coisas - $\mathrm{e}$ sem aqueles essas últimas perdem a sua identidade, ou, como diziam os antigos, perdem o seu ser. Identificar tais atributos seria o que de melhor pode almejar o conhecimento da forma pela qual organizamos objetos. E o instrumento linguístico para tal conhecimento é a cópula do ser interpretada como expressão de identidade. É impensável um estado de coisa no qual atributos essenciais não pertencessem às coisas. Atentar contra esse limite seria, mesmo, arriscar abandonar o comércio dos seres racionais.

Contudo, generalizar essa aplicação da cópula do ser ('é' em 'S é P') a todos os seus usos gera perturbações nos esquemas predicativos normais, análogas àquela do Mênon: obriga-nos a buscar uma misteriosa substancialidade de termos gerais postos na posição de sujeito em sentenças da forma 'S é P', presumivelmente a organizar todos os casos possíveis. Tal substancialidade deveria ser tão precisamente designada quanto no caso da nomeação individual. Por outro lado, deveria, ainda, subsistir incólume às enunciações dos seus enunciados - à maneira do objeto referido por um nome próprio. A esse tipo de estruturação conceitual, que gera problemas metafísicos no limite do dizível, ${ }^{5}$ virão responder os conceitos

\footnotetext{
${ }^{5}$ Para uma exposição sucinta desses problemas, ver
} Schmitz (2004, cap. 2). de aspecto e de semelhança de família.

A distinção entre predicação essencial e predicação acidental (ou concomitante) pode certamente mostrar-se esclarecedora de um aspecto importante da maneira como construímos e usamos conceitos. Mas um dos seus problemas é o de que, durante muito tempo, o substancialismo que lhe esteve associado levou os filósofos a pagarem um preço não desprezível, aquele de não atentarem para os elementos relativos à situação, ou contexto, dos enunciados, isto é, às enunciações, à sua ancoragem em gestos humanos capazes de pôr objetos, e não simplesmente conhecer a sua existência pressuposta, ainda que esse conhecimento (como no caso de Aristóteles) se dê pela via da experiência. Tais elementos foram considerados irrelevantes a uma investigação sobre o sentido, em parte pelas dificuldades e sutilezas do seu tratamento filosófico (em particular, dificuldades quanto à sua representação nalgum tipo de linguagem que indicasse as suas características universais). Em muitos projetos de fundamentação do conhecimento e do sentido, eles foram mesmo objeto não só de negligência, mas de delimitação com fins de desconsideração explícita para a própria criação do objeto a ser conhecido (pensamos, por exemplo, na linguística saussureana). A janela pragmática da dialética dos Tópicos de Aristóteles não se mostrou poderosa o suficiente, na sua fortuna crítica, para interferir no ascendente substancialista da Metafísica. Com isso, uma vasta zona da significação, ou da organização de objetos a que se submete, para o Wittgenstein tardio, até mesmo a própria percepção, ficou relegada a abordagens desprovidas de uma conceitualização mais adequada ou esclarecedora. Pensamos, aqui, em elementos relativos a tempo, ambiguidade, gradações na fronteira lábil entre o formal e o empírico, intersubjetividade, etc. - numa palavra: o que Wittgenstein chamava de aspectos.

Mais especificamente, a partir de Frege, filósofos preocupados com questões suscitadas pela lógica formal ${ }^{6}$ começaram a se mostrar in${ }^{6}$ No sentido usual de uma lógica para a qual se invente
uma notação concebida para fins específicos (no caso, a
lógica dita clássica). Faça-se a ressalva em razão de que
insinuar a aplicabilidade de uma noção de 'lógica infor- 
satisfeitos com as limitações do tratamento aristotélico do raciocínio. Um bom exemplo dessas limitações é a questão das relações. A silogística tradicional analisa uma proposição como 'Pedro é pai de João’ da seguinte maneira: diz-se de algo, Pedro, que é alguma coisa que contém, ou instancia, o predicado ‘pai de João’. A cópula funciona, aí, da mesma maneira como funciona em 'Pedro é homem'. Mas, se trocamos os nomes próprios da proposição por variáveis, como numa equação matemática, aparece algo que o paradigma baseado na forma proposicional única 'S é P' não é capaz de tratar: uma função justamente aquela relação ('ser pai de') em função da qual nós associamos uns aos outros, de maneiras especiais, os termos que se substituirão às variáveis. Além de um ganho de clareza a ser extraído da exibição da forma da relação como relação (p. ex., 'ser pai de’, como relação, é não simétrica e não reflexiva), evitam-se, dessa maneira, como se disse, problemas metafísicos suscitados pela postulação de uma substancialidade da coisa da qual se predica algo com a cópula 'é’, interpretada de uma única maneira. Em termos gerais: subsumimos uma variedade de laços de subordinação entre conceitos, ou de relações entre conceitos ou entre objetos e conceitos - incluindo-se aí enunciados de identidade do tipo das descrições definidas de Russell -, a um laço exclusivamente de pertencimento entre objetos e propriedades.

Em termos genealógicos, tanto Wittgenstein quanto Austin são herdeiros dessa inquietação com a lógica aristotélica (e com a sua ontologia substancialista) que vemos aparecer em textos da virada para o novecentos. E, em ambos, vemos o movimento comum de investigar as condições da significação de um ponto de vista que não exclua a linguagem tomada como um fenômeno no tempo e no espaço: o comportamento linguístico, ou, se se quiser, no limite, a ação significativa. Mas o seu campo comum de recusa da substância de tipo

mal' pode levar a preconceitos desinteressantes, pensamos nós. A menos, talvez, que se venha a consagrar algum uso de 'informal' como, justamente, 'não provido de uma notação para fins específicos'. aristotélico logo vem a dar lugar a uma sutil divergência de fundo entre eles, relativa ao tratamento filosófico do fenômeno da significação em âmbito pragmático.

Para Wittgenstein, uma investigação sobre o sentido será sempre uma investigação sobre algum tipo de articulação formal com determinações internas suficientes à objetividade do significado. Será formal e objetiva na medida em que passível de ser posta em definições públicas ${ }^{7}$ e por escrito, seguindo a sugestão fregeana, ${ }^{8}$ e colherá, no campo dos usos linguísticos, critérios para as interdições, necessidades e possibilidades que constituem tais usos.

Austin, pela sua parte, tomará um caminho não autonomista. O recurso de Austin a amostras de uso efetivo de uma linguagem natural em contextos cotidianos de ação linguística parece prender-se com uma espécie de critério falibilista para as suas investigações filosóficas da significação. Daí poder ele dizer que fugir à metafísica e ao dogmatismo "pode estimular-nos a voltar a levar em conta [sopesar] quais são realmente os fatos na sua complexidade efetiva" (1961, p.33). ${ }^{9}$ É dessa fonte, ou seja, da recondução da atenção para amostras de usos da linguagem considerada na sua dimensão empírica, que se devem esperar bons resultados em termos de esclarecimentos de

${ }^{7}$ Público, aqui, opõe-se a privado. Privada diz-se não de uma linguagem apenas falada por uma pessoa em termos empíricos, mas, antes, de uma linguagem cujas associações preparatórias mais básicas entre signos e objetos de remetimento pudessem firmar-se num âmbito puramente mental, remetendo signo a sensação. É evidente que isso é uma vivência que, na nossa forma de vida, só concebemos poder ser de uma pessoa - "no sentido em que eu posso ter uma máquina de costura privada” (MS 166 4r, in N), diz Wittgenstein, e de forma tal, que outras pessoas não necessariamente soubessem disso. Mas esse ponto não é essencial ao argumento contra a possibilidade duma linguagem privada. $\mathrm{O}$ essencial ao argumento é o vazio criterial que torna impossível o arranque de uma linguagem a partir da ocorrência de uma sensação e subsequente remetimento de um signo, S, a essa sensação - o presumível primeiro remetimento entre signo e objeto, que inaugurasse uma língua. A prova disso é que o argumento também poderia ser exemplificado, sem perda de eficácia, usando-se, por exemplo, o povo Borg, da série Star Trek (Jornada nas Estrelas), que possui uma mente coletiva, e no qual, portanto, um indivíduo não pode ter "uma máquina de costura [pensamento] privada”. Ver Star Trek - First Contact, 1996.

${ }^{8}$ Cf. Moreno (2006, p. 152).

9 "[...] may encourage us to consider again what the facts in their actual complexity really are”. 
impasses filosóficos, de conceitos filosóficos. A filosofia de Austin parece querer emular-se junto ao método científico experimental: testar hipóteses em ambientes controlados (situações de enunciação) e arriscar generalizações tipológicas (de atos de fala), explicitamente abertas a revisões - como mostra o estilo de Austin, sempre pronto a recomeçar tudo novamente do zero. ${ }^{10}$

Também em Wittgenstein encontramos tal recondução da atenção filosófica à linguagem em usos efetivos. No entanto, os objetivos dos dois filósofos são diferentes - embora não à primeira vista, tampouco sob todos os aspectos. O trabalho terapêutico referido no §116 das Investigações filosóficas ${ }^{11}$ não mobiliza uma dimensão empírica como tal dos usos da linguagem, mas, sobretudo, amostras de situações em diversas variações de aspectos de uso, ainda que imaginárias, porventura contraintuitivas ou mesmo absurdas, com o objetivo de exibir as modalidades atuantes em cada conceito, em cada jogo de linguagem. O essencial é percorrer ligações intermediárias ${ }^{12}$ (em amostras empiricamente colhidas ou não) entre conceitos, proposições, nomes, etc., que propiciem uma visão panorâmica de um jogo, i.e., que nos permitam uma sua análise completa. Completa, posto que esclarecedora de um dado uso, mas não definitiva, posto que as ligações intermediárias podem mudar com o uso no tempo. Completa, também, porque não gerada no contexto dum programa de pesquisa que visasse a integrá-la a alguma tábua tipológica exaustiva, mas tão somente dissolver uma obscuridade metafísica ensejada pelo próprio olhar filosófico.

Será útil, aqui, comparar os sentidos que podemos encontrar em Wittgenstein e em Austin das expressões ordinary language e alltäglich Sprachetraduzíveis, em princípio, uma pela outra (lingua-

\footnotetext{
${ }^{10}$ Não temos espaço para fundamentar, aqui, tal atitude, que esperamos que leitores de How to Do Things with Words haverão de reconhecer.

11 "Quando os filósofos usam uma palavra - “saber”, “ser”, "objeto", "eu”, "proposição”, "nome” - e procuram apreender a essência da coisa, deve-se sempre perguntar: essa palavra é usada de fato desse modo na língua em que ela existe?” (Trad. Bruni, 2001, Col. os pensadores).

${ }^{12}$ Ver Azize (2010).
}

gem ordinária, ou cotidiana). O recurso à linguagem ordinária, em Wittgenstein, faz parte da investigação do processo simbólico de autonomização de modalidades (necessário, suficiente, possível) com relação a determinações que antecedessem a ação humana de criar relações, identidade, etc. Estamos diante de uma concepção segundo a qual a linguagem opera de forma transcendental, ainda que sua base convencional mostre que o seu campo transcendental não é puro, podendo-se lançar mão de elementos empíricos em estágios preparatórios das cadeias de interdições e ligações que perfarão um dado jogo de linguagem (Moreno, 2006) - e até mesmo em jogos já estruturados (Quando começa a "vida" no processo de gestação? Como se diferencia o arbusto da árvore? etc.). Por um lado, a investigação dos fundamentos do significado termina por encontrar-se com um limite de gestos humanos arbitrários que traçam distinções na empiria, de forma a introduzir paradigmas na linguagem (como o conhecido exemplo do metro-padrão)..$^{13}$ Por outro lado, o que caracteriza o uso normal, ou cotidiano, de conceitos, na perspectiva de Wittgenstein, é a negação de usos metafísicos, e não o seu aspecto empírico per se (Baker, 2002), ou, como diria Austin, "quais são realmente os fatos na sua complexidade efetiva". Quando digo que posso conceber uma flecha que aponte na direção contrária à sua seta (ou seja, que concebo vê-la como uma flecha que significa dessa maneira, segundo esse aspecto do conceito de apontar), o que faz desse um enunciado da linguagem cotidiana é a negação de um enunciado metafísico implícito, qual seja, o enunciado modal de que não posso vê-la dessa forma, segundo esse aspecto. ${ }^{14} \mathrm{O}$ que Wittgenstein chamava de alltäglich Sprache não se confunde, portanto, senão parcialmente (do ponto de vista dos

${ }^{13}$ Para a operação linguística de propor paradigmas, ou amostras candidatas a objetos em jogos de linguagem, ver Salles (2002).

${ }^{14}$ É importante insistir em que se trata de um enunciado modal, se não queremos recuar da sugestão de Gordon Baker, deixando de fazer justiça ao fraseamento de Wittgenstein. Nesse sentido, Katherine Morris, colaboradora do Baker tardio, chama a atenção para que os frequentes "Aqui poderíamos dizer que", e as perguntas sobre significados ("Devemos então dizer que...?"), a não serem interpretados efetivamente como enunciados modais, abrem as portas, comumente, a interpreta- 
objetivos do seu "novo método") com aquilo que Austin chamava de ordinary language.

Associado a esse, há ainda outro aspecto a distinguir os dois tratamentos da linguagem cotidiana, já referido, e que gostaríamos de ressaltar. É que a investigação da alltäglich Sprache não se insere num programa que almejasse uma classificação tipológica da ação linguística, buscando, um dia, estabelecer a validade universal, teórica, de, por exemplo, um número determinado de categorias de atos de fala - número, de resto, que a ulterior pesquisa empírica poderia modificar. A variação de aspectos wittgensteiniana opera caso a caso: é confessadamente uma casuística, e os seus objetivos são tão somente terapêuticos - uma profilaxia contra o dogmatismo, filho da perplexidade filosófica. É, aliás, a essa última que se dirige a recondução da atenção à linguagem nos seus usos efetivos. Não para "enumerar usos efetivos de palavras" (BB, p. 28). Ali, onde o trabalho do "gramático filosófico [...] duplica aquele do lexicógrafo" (ver nota 1), ele o faz, em todo o caso, “com um objetivo diferente" (Kennick 1971, p. 146), qual seja, "reunir recordações para um determinado fim" (PU §127). Esse fim não é classificatório, categorizante, e, no caso de Wittgenstein, tampouco é tético ou propositivo (ainda que teorias possam nele se inspirar profilaticamente); trata-se de "limpar a questão, expor a sua natureza gramatical, de forma que o problema não seja resolvido no sentido em que problemas matemáticos ou científicos são amiúde resolvidos, mas se dissolva ou desapareça." (1971, p. 147).

Nesta altura, uma comparação entre Wittgenstein e Austin segundo os aspectos acima sugeridos exigiria que nos debruçássemos sobre os textos de maneira mais detida, o que não é o caso neste espaço. Lancemos mão, como alternativa retórica, de um gesto à maneira de Max Weber, e

ções que colhem, nos textos wittgensteinianos, teorias (realistas, behavioristas, idealistas, etc.) acerca dos temas que são objeto da terapia filosófica. "Nas raras ocasiões em que [os recursos textuais de W.] não são ignorados, são tratados de forma não modal (p. ex., Hallett trata o preâmbulo "Eis aqui uma possibilidade" como a introdução de um contraexemplo a uma generalização)" (Morris, 1998 , p. 295). Ver também Hutchinson 2008. criemos tipos ideais, assim delineando esquematicamente a diferença que nos importa relevar. Imaginemos, então, um diálogo contra o já referido pano de fundo comum antiessencialista que é o de Austin e Wittgenstein, entre um pragmático empirista e um pragmático gramatical. Comecemos pela voz da primeira personagem.

Na perspectiva de certa pragmática empirista, se quisermos falar de um determinado jogo de linguagem de forma esclarecedora, teremos sempre de nos ater a Callias, e nunca subir um nível e falar do homem Callias; temos sempre de nos ater ao doente (termo individual), e nunca falar da doença (termo universal). Abstrair de Callias ou do doente seria cometer a falácia do ponto de vista neutro ou de lado nenhum: necessariamente introduziríamos delírios acerca de como achamos que as coisas são fora da sua temporalidade experiencial e da sua historicidade. Introduziríamos uma episteme que, de alguma maneira, se assentaria numa ontologia das modalidades aléticas (necessário, contingente) - vocabulário inútil à compreensão do tipo de experiência diacrônica da qual o empirista quer extrair conhecimento. Numa certa perspectiva empirista, então, isso não é esclarecedor, e, portanto, não é desejável, porque constitui uma imposição do olhar do investigador sobre a contingência social, sobre as narrativas no tempo, sobre a abertura para os testes da experiência. Uma investigação esclarecedora sobre determinada gramática precisa sair das remissões inferenciais internas ao uso do simbolismo linguístico, e introduzir dados (políticos, sociológicos, etc.) colhidos no campo da ação significativa como tal. O horizonte do trabalho é o da construção de uma tábua tipológica, e o seu método é empírico e experimental.

É possível apresentar outro programa de investigação, igualmente pragmático, posto que não purga o campo de análise de elementos situacionais, mas que, para assestar a atenção nos dados linguísticos, tampouco sacrifica uma certa dimensão transcendental de critérios de uso da linguagem e da ação significativa. Forçando um pouco as coisas, diríamos que o empirista 
que viemos de convocar defende que não é desejável passar da atualidade à potencialidade, ou da palavra ao conceito (ou, se se quiser, da verdade ao sentido), porque, com isso, eliminamos o vivido intuitivo ou temporal da nossa investigação, e ficamos relegados a uma forma pura ou canônica dos conteúdos possíveis: tornamo-nos, necessariamente, dogmáticos, quiçá lamentavelmente transculturais. Ele assume o que Arley Moreno chama de uma barreira entre o empírico e o formal (2007, p. 69) que, nesse sentido, parece ser análoga àquela do Tractatus - mas escolhe ficar com a empiria como solo da investigação. Para o nosso empirista, dizer que alguém propõe conceitos é um anátema: há que se ficar com Callias, com a palavra na dimensão contingente da sua enunciação, e divisar um programa de investigação que vise à sua classificação progressivamente exaustiva.

No entanto, quando olhamos mais de perto para a forma que se exibe nos jogos de linguagem, vemos que a estabilidade dos jogos, ainda que aberta a novas regras, depende de ligações internas entre conceitos. Essas ligações nascem de gestos humanos - e aqui, contra o idealista, o formalista se alia ao nosso empirista, inventando um formalismo não puro, integrando a vida à forma. Mas esses gestos - ao iniciarem uma cadeia de níveis lógicos, ou seja, quando as estipulações paradigmáticas mais básicas da linguagem, ou paradigmas primários, assumem uma função transcendental de organização de objetos - transcendem as situações empíricas nas quais amostras do mundo foram propostas para assumir a função de padrões de regulação de objetos (cor > gradações > vermelho)..$^{15}$ Aqui, o formalista não puro rompe aquela barreira entre o formal e o empírico que havíamos mencionado, seguindo Arley Moreno - e se afasta tanto do formalista puro tractariano quanto do "empirista puro". Passa, então, a dizer o seguinte: por um lado, é compreendendo critérios de organização linguística logicamente prévia à experiência significativa que esclarecemos um dado uso no tempo e

${ }^{15}$ Ver Salles (2002). no espaço. Mas, por outro lado, isso não implica nem dogmatismo nem idealização num sentido platônico (como se toda necessidade carregasse a força ontológica de um 'não poderia ser de outro modo', como se toda necessidade implicasse não se integrar a ação humana à organização dos seus objetos). Por quê? Justamente porque esses critérios modais têm uma origem arbitrária, em gestos humanos. São fundamentos sem fundamento. Em cada jogo, o uso adequado depende de não violarmos a sua gramática, que está prevista nos seus momentos básicos de organização (“2m”, relativamente ao sistema decimal, e este relativamente à noção de sistema de medida, à espacialização do tempo, etc.). Perguntas que não respeitem essa gramática, que nos remetam para fora do seu campo transcendental, nos deixam desorientados, nos barram a possibilidade de um esclarecimento de tipo filosófico, porque introduzem uma regressão infinita para causas contingentes. ${ }^{16}$ Vedado o acesso ao formal objetivo, resta-nos os conteúdos subjetivos, empíricos. Mas esses, justamente, não são comparáveis nesse nível da exibição das modalidades, e, portanto, não podemos esclarecê-los num sentido filosoficamente relevante. De modo algum sugerimos que tratamentos estritamente empíricos do fenômeno da significação sejam menos interessantes ou esclarecedores, como que por veleidade de reinstaurar alguma nova forma de filosofia como ciência primeira, desdenhosa de olhares como o do linguista ou do antropólogo. Mas há que distingui-los do ponto de vista filosófico - tarefa importante num momento em que precisamente o olhar filosófico parece tantas vezes descaracterizado por uma redução sua a momento preparatório das ciências empíricas (o discurso de divulgação das ciências cognitivas é talvez exemplar a esse respeito).

Sugerimos que é possível construir uma narrativa genealógica segundo a qual a rejeição do essencialismo aristotélico constituiu um ponto de

${ }^{16}$ De passagem, observemos que também nos deixariam sem reação possível perguntas que fossem feitas num contexto vital demasiado heterogêneo - o que novamente aproxima os nossos dois tipos filosóficos ideais. "Se um leão pudesse falar, não o entenderíamos." (PU Parte II, seção XI). 
partida comum a Austin e a Wittgenstein. Tratarse-ia, agora, de olhar para a linguagem sem certa imagem unilateral das formas predicativas do ser, de olhar para a maneira como o simbolismo linguístico exibe critérios de sentido que se multiplicam internamente, sim, mas em conexão íntima com as demais ações significativas humanas. Em termos muito gerais, trata-se de elidir a imagem tradicional de uma região de significação que seja, quer anterior (as formas ou substâncias), quer exterior (critérios empíricos vistos como causas) à articulação de regras no uso efetivo da linguagem, à prática - no limite, por que não dizê-lo, à experiência (no sentido de ação significativa). É nesse sentido que "a linguagem deve responder por si própria” (PG I, § 1). Embora assente na empiria, a concepção wittgensteiniana da linguagem enseja uma noção de conceito (aí incluídos os atos de fala austinianos) que remete, não apenas para a experiência do comportamento linguístico e o seu tratamento tipológico, como no caso de Austin, mas para o formal nessa experiência, ou seja, para um campo que é transcendental a despeito de manter os pés no solo empírico, um campo, afinal, de modalidades: os limites, a um tempo casuísticos e essenciais, do que devemos e do que podemos dizer. Esses limites apontam para a forma... da nossa vida.

Recebido para publicação em 12 de outubro de 2012 Aceito em 04 de novembro de 2012

\section{REFERÊNCIAS}

AUSTIN, J. L. The Meaning of a Word. In: URMSON, J O.; WARNOCK, G. J. (Ed.) Philosophical papers. Oxford: Clarendon Press, 1961. p.23-43.

AZIZE, Rafael Lopes. Ligações intermediárias e representação perspícua em Wittgenstein. Dissertatio, Pelotas, n.31, p.119-132, inverno, 2010.

BAKER, Gordon. 2002. Wittgenstein on metaphysical/ everyday Use. In: MORRIS, Katherine (Ed. e Intr.. Wittgenstein's method: neglected aspects. Malden, MA Blackwell, 2004. p.22-51.

GRICE, Paul. 1987. Conceptual analysis and the province of philosophy. In: Studies in the way of words. Cambridge: Harvard U.P., 1989. p.181-185.

HUTCHINSON, Phil; READ, Rupert. Toward a perspicuous presentation of 'perspicuous presentation'. Philosophical Investigations, Oxford, Wiley-Blackwell, v.31, n.2, apr., p.141-160, 2008

KENNICK, W. E. Philosophy as grammar and the reality of the universals. In: AMBROSE, Alice; LAZEROWITZ, Morris. (Ed.) Ludwig Wittgenstein - philosophy and language. Londres: George Allen \& Unwin, 1971. p.140-185.

MIGUENS, Sofia. Resenha de; TRAVIS, Charles. Thought's footing: themes in Wittgenstein's philosophica investigations [Oxford, 2006]. Disputatio, Lisboa, v.2, n.22, p.146-152, 2007.

MORENO, Arley R. Lógica, linguagem, pragmática: reflexões sobre forma e conteúdo. In: (Org.) Wittgenstein - ética, estética, epistemologia. Campinas: Unicamp, 2006. p.143-155. (Coleção CLE,v.43)

Pensamento e realidade: em direcão a uma pragmática filosófica. In: _ (Org.) Wittgenstein - as pectos pragmáticos. Campinas: Unicamp, 2007. p.55-94 (Coleçẫo CLE, v.49).

MORRIS, Katherine. The 'context principle' in the later Wittgenstein. The Philosophical Quarterly, v.44, n.176, p.294-310,1998.

RUSSELL, B. My philosophical development. New York: Simon and Schuster, 1959. p.216-217.

SALLES, J. C. A gramática das cores em Wittgenstein. Campinas: Unicamp, 2002. Coleção CLE, v.35).

SCHMITZ, François. Wittgenstein. Trad. José Oscar de Almeida Marques. São Paulo: Estação Liberdade, 2004. cap.2. 183p.

STAR trek: first contact . Direção Jonathan Frakes .[S.l.] 1996 (111min.) son. color

\section{REFERÊNCIAS - Wittgenstein, Ludwig}

BB - The Blue and Brown Books - Preliminary Studies for the 'Philosophical Investigations'. New York: Harper \& Row, [1958]1965.

GB - Remarks on Frazer's Golden Bough / Bemerkungen über Frazers Golden Bough, (Ed. bil.). In: Philosophical Occasions 1912-1951. J. Klagge e A. Nordmann, (Ed.) Indianapolis/Cambridge: Hackett, 1993. p.118-154.

$\mathrm{N}$ - Wittgenstein's Nachlass - The Bergen Electronic Edition, Oxford U.P./Univ. of Bergen, 2000.

PB - Philosophische Bemerkungen. Rush Rhees (Ed.) Frankfurt: Suhrkamp, 1970. Trad inglesa Philosophical Remarks. Trad. de R. Hargreaves e R. WhiteBlackwell, 1975.

PG - Philosophische Grammatik. Rush Rhees (Ed.), Frankfurt: Suhrkamp, 1973. Trad. inglesa Philosophical Grammar. Trad. de A. Kenny, U. of California Press, 1974

PU - Philosophical Investigations / Philosophische Untersuchungen, 3 ed, RHEES, R. (Ed. Bil.) G.E.M. Anscombe. Tr. G.E.M. Anscombe, Blackwell, 2001. Trad. bras. Investigações FilosóficasWittgenstein, 5.ed., Trad. de J.C. Bruni, São Paulo: Nova Cultural, 2001(Coleção os pensadores). Trad. port. M.S. Lourenço, 2.ed., Gulbenkian, 1995).

Z - Zettel (Ed. bil., org.) G.E.M. Anscombe e G.H. von Wright. Trad. G.E.M. Anscombe, Berkeley: Un. of California Press, 1967. Trad. port. Fichas, Trad. Ana B. da Costa, Lisboa: Ed. 70, 1989. 


\section{LINGUISTIC BEHAVIOR, EMPIRICAL REALM AND PHILOSOPHY IN WITTGENSTEIN}

\author{
Rafael Lopes Azize
}

In the 1940s, Wittgenstein deepens his expansion of the criterial field of concepts and the possible and desirable analysis thereof, towards a greater inclusion, in the formal, of the lived. This paper examines some questions pertaining to the charge that, by widening the realm of conceptual analysis towards Praxis (or, as the philosopher put it, "ritual behavior"), Wittgenstein would have disparaged his philosophical sensibility into strictly empirical - thus philosophically irrelevant investigations.

KeY-words: Ordinary Language. Linguistic Behavior. Pragmatics. Autonomy of Sense. Austin. Wittgenstein.

\section{COMPORTEMENT LINGUISTIQUE, EMPIRIE ET PHILOSOPHIE CHEZ WITTGENSTEIN}

\author{
Rafael Lopes Azize
}

Dans les années 1940, Wittgenstein approfondit l'expansion du champ des critères concernant les concepts et de leur analyse possible et souhaitable dans le sens d'une plus grande inclusion, dans le formel, du vécu. Cet article analyse certaines questions relatives à l'accusation selon laquelle, en élargissant le champ de l'analyse conceptuelle à la pratique (ou, comme le disait le philosophe, au "comportement rituel”), Wittgenstein aurait dévié sa sensibilité philosophique vers des investigations strictement empiriques, donc sans importances.

Mots-CLÉs: Langage Ordinaire. Comportement Linguistique. Pragmatique. Autonomie du Sens. Austin. Wittgenstein.

Rafael Lopes Azize - Doutor em Filosofia. Professor do Departamento de Filosofia da Universidade Federal da Bahia. Membro dos Grupos de Pesquisa do CNPq Filosofia da Linguagem e do Conhecimento e Filosofia Moderna e Contemporânea. Tem experiência na área de filosofia, com ênfase em filosofia da linguagem e do conhecimento, atuando principalmente nos seguintes temas: teorias do simbolismo e do significado; linguagem, ação e percepção; interpretação e análise sistemática da filosofia de Wittgenstein, exame das suas influências e do seu legado, particularmente nos campos da linguagem, do conhecimento, da filosofia da psicologia e da antropologia. Publicações recentes: Ligações intermediárias e representação perspícua em Wittgenstein. Dissertatio, Pelotas, UFPel, n.31, p. 119-132, 2010; O pano de fundo das regras. Certeza, Salvador, Quarteto, p. 187-199, 2012. 
